\title{
Biosimilars: what the oncologist should know
}

\author{
Marc Thill*,1, Nicholas Thatcher ${ }^{2}$, Vladimir Hanes ${ }^{3}$ \& Gary H Lyman ${ }^{4}$ \\ ${ }^{1}$ Department of Gynecology and Gynecological Oncology, Agaplesion Markus Hospital, Frankfurt am Main, Germany \\ ${ }^{2}$ Department of Medical Oncology, The Christie Hospital, Manchester, UK \\ ${ }^{3}$ Amgen, Inc., Thousand Oaks, CA 91320, USA \\ ${ }^{4}$ Public Health Sciences and Research Divisions, Fred Hutchinson Cancer Research Center, University of Washington School of \\ Medicine, Seattle, WA 98109, USA \\ *Author for correspondence: Tel.: +49 699533 2228; Marc.Thill@fdk.info
}

As originator biologic medicines lose patent protection, some biopharmaceutical companies are focusing on developing similar versions of these costly and complex therapies with a goal of providing more affordable treatment options. Many of these molecules, known as biosimilars, are now approved worldwide and several more are expected to be introduced in the near future. As more biosimilars become available, it is important for clinicians to become familiar with this new category of products and understand how biosimilars are developed, how their development differs from that of originator biologics and how they differ from generics. This review aims to provide the practicing clinician with the knowledge needed to understand biosimilars, along with some guidance on their use in treating oncologic diseases.

First draft submitted: 19 September 2018; Accepted for publication: 19 December 2018; Published online: 22 February 2019

Keywords: biosimilars $\bullet$ extrapolation $\bullet$ monoclonal antibodies $\bullet$ oncologic biosimilars

An increasingly greater proportion of life-saving therapies now include complex biologics. More and more cancer therapeutics and medications used for inflammatory diseases are counted among this growing class of agents. However, biologics can be expensive and as originator biologics begin to lose their patent protection, some biopharmaceutical companies are directing resources on developing 'similar' versions of these costly and complex therapies. One of the goals of developing these molecules, known as biosimilars, is to provide additional treatment alternatives. Several biosimilars are now approved worldwide for treatment of cancer and supportive care [1-3]. As more biosimilars become available, it is important that clinicians and healthcare providers (HCPs) familiarize themselves with this new category of products and understand how they are developed. Considering that cancer treatments are expected to form a major proportion of biosimilar products, and biologics are often a critical part of oncology treatments [4], it will be particularly important for oncologists to educate themselves in this area.

This review presents an overview of our knowledge regarding biosimilars. Here, we aim to provide the practicing oncologist with the fundamental knowledge required to understand this emerging category of products, its use and potential benefits in treating oncologic diseases. While there are several considerations for discussion with respect to biosimilars, such as pharmacoeconomics, physician perspectives and patient preferences, each of which merits a standalone review, here, we focus on the scientific, clinical, regulatory and manufacturing perspectives related to the development of these products.

\section{Definition of biologics \& biosimilars}

Biologics are drug products derived from genetically modified cell lines and range in diversity from relatively simple recombinant proteins to large complex monoclonal antibodies (mAbs). Because of their complex physicochemical structures and the complicated processes by which they are manufactured, biologics are considerably more expensive to manufacture than their more familiar small-molecule pharmaceutical counterparts. Unfortunately, the increasing availability and use of these medicines has contributed to an increasing share of healthcare spending.

While different regulatory authorities vary in their specific definition of biosimilars (Table 1) [5-9], the underlying definition is that a biosimilar is a biologic agent that is highly similar structurally to its originator reference product (RP), with no clinically meaningful differences in function, purity, potency, pharmacokinetics (PK), 
Table 1. Worldwide regulatory definitions of biosimilars.

\begin{tabular}{|c|c|c|}
\hline Regulatory authority & Definition & Ref. \\
\hline EMA & $\begin{array}{l}\text { A biosimilar is a biological medicine highly similar to another already approved } \\
\text { biological medicine (the 'reference medicine'). } \\
\text { (Biosimilars are approved according to the same standards of pharmaceutical } \\
\text { quality, safety and efficacy that apply to all biological medicines) }\end{array}$ & $\begin{array}{l}\text { The European Medicines Agency. Biosimilar } \\
\text { Medicines. (2017) [5] }\end{array}$ \\
\hline US FDA & $\begin{array}{l}\text { A biosimilar is a biologic product that is highly similar to a US-licensed RP, } \\
\text { notwithstanding minor differences in clinically inactive components, and for which } \\
\text { there are no clinically meaningful differences between the biological product and } \\
\text { the RP in terms of the safety, purity and potency of the product }\end{array}$ & $\begin{array}{l}42 \text { US Code } \S 262(\mathrm{i})(2) \text { - Regulation of } \\
\text { biological products [6] } \\
\text { FDA guidance for Industry: questions and } \\
\text { answers regarding BPCIA (2015) [7] }\end{array}$ \\
\hline Jp-PMDA & $\begin{array}{l}\text { A biosimilar is a FOBMP that is a new biotechnological medicinal product developed } \\
\text { to be similar to an already licensed, biotechnology medical product, i.e., the } \\
\text { original biologic product or RBP; it is developed on the basis of data that } \\
\text { demonstrate comparability between the FOBMP and the RBP with respect to } \\
\text { quality, safety and efficacy or other relevant data }\end{array}$ & $\begin{array}{l}\text { Japan Generic Medicines Association, Nov } \\
\text { 25, } 2010 \text { Interim Translation of Notification } \\
\text { ELD, PFSB, MHLW; Yakushokushinsa } \\
\text { No0304007 (Mar 4, 2009) [8] }\end{array}$ \\
\hline WHO & $\begin{array}{l}\text { A biosimilar is an SBP, defined as 'a biotherapeutic product, which is similar in terms } \\
\text { of quality, safety and efficacy to an already licensed reference biotherapeutic } \\
\text { product' }\end{array}$ & $\begin{array}{l}\text { WHO Guidelines on Evaluation of Similar } \\
\text { Biotherapeutic Products. (2009) [9] }\end{array}$ \\
\hline
\end{tabular}

pharmacodynamics (PD), clinical efficacy, safety and immunogenicity despite minor differences in clinically inactive components [9-12]. It is important to note that each of the regulatory definitions highlights a basic requirement that the proposed biosimilar and the originator RP are shown to be similar in analytical (structural and functional), preclinical and clinical attributes.

\section{Generics versus biosimilars}

An understanding of what biosimilars are should go hand-in-hand with an understanding of what they are not. Biosimilars are not generics. Generic drugs are exact copies of their reference drugs in all attributes, including chemical structure, strength, dosage, route of administration, safety profile and indication. Generic drugs are relatively small molecules with simple and well-characterized chemical structures (Figure 1); they are produced by chemical synthesis, using well-defined manufacturing processes that result in predictable outcomes [13]. On the other hand, biosimilars are not replicas of their RP. Like their RPs, biosimilars are larger and more complex proteins. They are produced in living cells and their structure and stability are influenced by multiple factors that include, among others, the cell line and temperature at which they are produced, their purification process and storage conditions [13]. Any difference in any one of these factors may alter the final product in unpredictable ways. As a result, biosimilars are considered as inherently unique yet highly similar molecules. Although they have similar structural and functional attributes with their originator RP, there may be minor differences between the two. Different biosimilars of a single RP may also differ from one another [14].

\section{Development of biosimilars}

The development of biosimilars and the pathway to their regulatory approval is unique and differs from that for originator biologics as well as generic drugs (Table 2). At the outset, biosimilar product development requires a comprehensive understanding of the complex molecular structure as well as the functional properties of the RP (Figure 2) $[10,15,16]$. Importantly, the critical quality attributes (CQAs) of the biologic agent should be clearly identified. CQAs refer to those characteristics of the RP that are essential to, or important (in varying degrees), for its biological function and ultimately for efficacy and safety. In the context of drug product manufacturing, these attributes include physical, chemical, biological and microbiological attributes that can be clearly defined, measured and monitored on an ongoing basis to assure that the final product remains within acceptable limits of quality [17]. The number of CQAs may vary between products and can be extensive. For example, a mAB may have more than $40 \mathrm{CQAs}$; based on a scientific understanding of how these attributes influence safety, efficacy, immunogenicity and/or PK/PD, these attributes may need to be evaluated using more than 50 different assays (Table 3) [15,18]. It is also important to understand that despite having the same amino acid sequence as the reference, post-translational modifications (PTMs) may occur even after the proposed biosimilar is synthesized. Such PTMs may result in the generation of low-level variants with altered function or stability. Various factors such as the cell line, mutations therein, or culture conditions, may contribute to PTMs. Since variations between a proposed biosimilar and its 


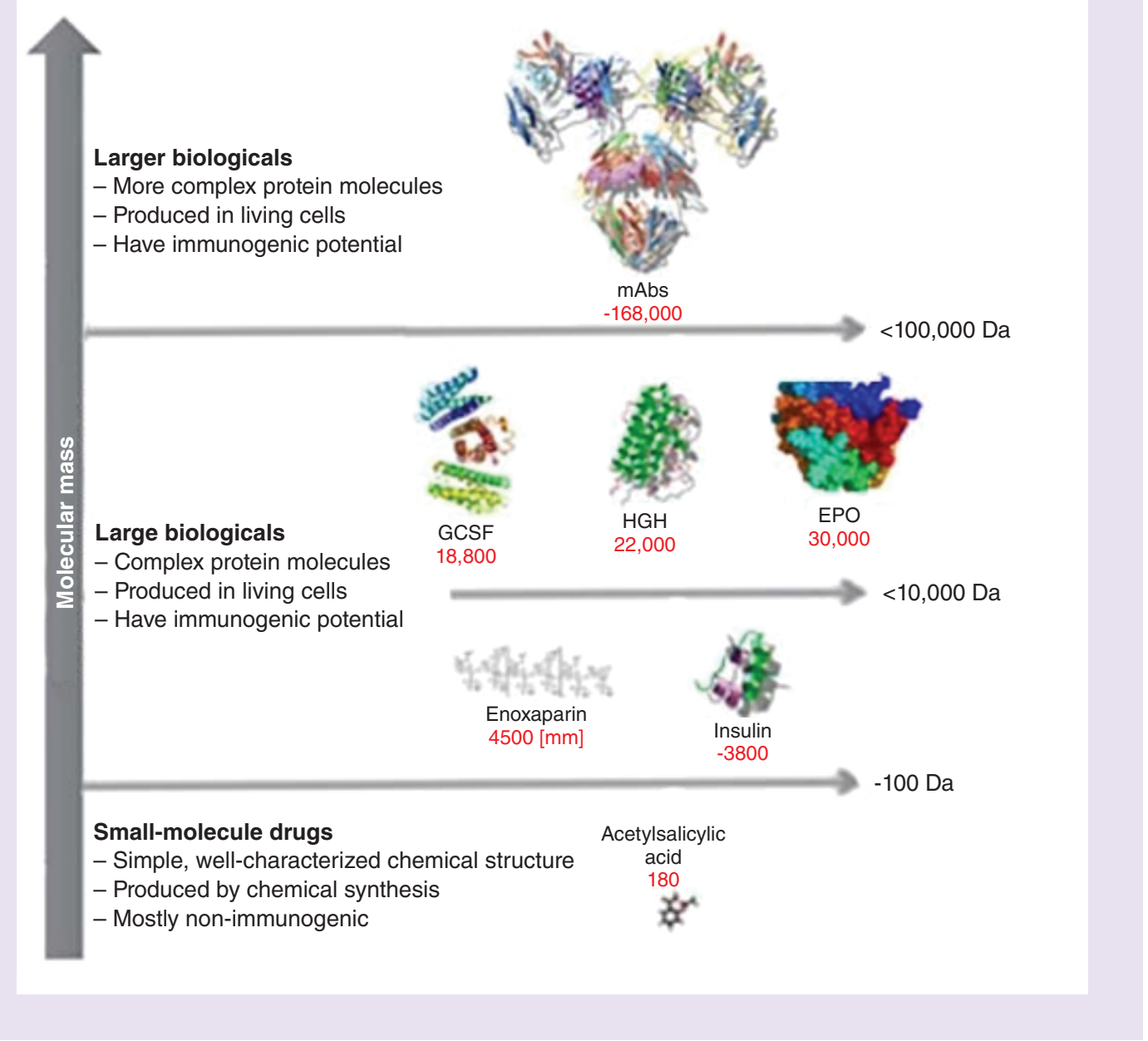

Figure 1. Molecular weight comparisons: small-molecule drugs versus larger biologicals. Not drawn to scale. Adapted from [13].

Ave: Average; Da: Daltons; EPO: Erythropoietin; mAbs: Monoclonal antibodies.

RP can impact pharmacologic activity and immunogenic potential as well as clinical efficacy and safety of the biosimilar, it is important to identify and quantify them early in the product development process [19-21].

An important point to bear in mind during the development of biosimilars is the understanding of the difference between comparability and biosimilarity. Comparability refers to a postapproval manufacturing change made to a biologic product by the product's manufacturer. Such changes to the manufacturing process are relatively common and may include a change in manufacturing equipment or changes made to scale-up yield or to reduce impurities, and so forth. Comparability of the products before and after the manufacturing changes have been made assures that the product has retained its attributes. Thus, there is no expectation of adverse effect on the safety or efficacy of the product after the change [13]. Such manufacturing changes are successfully made because the product manufacturer has an exhaustive understanding of the product, including its development history. This does not imply that over time the biologic becomes a biosimilar of itself. Biosimilarity, on the other hand, describes the concept whereby a manufacturer develops a molecule to be similar in structure and function to an existing product, the RP. A biosimilar is manufactured anew without any prior knowledge of the developmental history of the RP; for this reason, a biosimilar can never be an exact replica of its RP. In this case, demonstration of biosimilarity is based on a comprehensive comparative characterization of the proposed biosimilar that is produced using a new/different cell line developed by a new/different manufacturer. 


\begin{tabular}{|c|c|c|c|c|c|c|}
\hline \multirow[t]{2}{*}{ Type of agent } & \multirow{2}{*}{$\begin{array}{l}\text { Quality assessment/ } \\
\text { analytical } \\
\text { characterization }\end{array}$} & \multirow{2}{*}{$\begin{array}{l}\text { Pre-clinical } \\
\text { assessment }\end{array}$} & \multicolumn{3}{|c|}{ Clinical testing } & \multirow[t]{2}{*}{ Postapproval studies } \\
\hline & & & Phase I & Phase II & Phase III & \\
\hline Originator biologic & $\begin{array}{l}\text { Requires } \\
\text { comprehensive } \\
\text { analytical (structure } \\
\text { and function) } \\
\text { characterization }\end{array}$ & $\begin{array}{l}\text { Requires } \\
\text { comprehensive } \\
\text { preclinical assessment }\end{array}$ & $\begin{array}{l}\text { Required (healthy } \\
\text { subjects) need to } \\
\text { assesses } \\
\text { safety/tolerability } \\
\text { and PK/PD }\end{array}$ & Required & $\begin{array}{l}\text { Required in all } \\
\text { proposed indications }\end{array}$ & $\begin{array}{l}\text { Risk management plan } \\
\text { (EU only). } \\
\text { Pharmacovigilance } \\
\text { program/safety } \\
\text { monitoring }\end{array}$ \\
\hline Biosimilar & $\begin{array}{l}\text { Requires } \\
\text { comprehensive } \\
\text { comparative } \\
\text { analytical (structure } \\
\text { and function) } \\
\text { characterization }\end{array}$ & $\begin{array}{l}\text { Extensive } \\
\text { characterization } \\
\text { required, including } \\
\text { MOA assessments }\end{array}$ & $\begin{array}{l}\text { PK/PD similarity or } \\
\text { equivalence studies } \\
\text { required. } \\
\text { PD studies - if } \\
\text { appropriate marker is } \\
\text { available }\end{array}$ & Not required & $\begin{array}{l}\text { Required in at least } \\
\text { one representative } \\
\text { indication. } \\
\text { Extrapolation to } \\
\text { other indications } \\
\text { based on scientific } \\
\text { justification }\end{array}$ & $\begin{array}{l}\text { Risk management plan } \\
\text { (EU only). } \\
\text { Pharmacovigilance } \\
\text { program/safety } \\
\text { monitoring }\end{array}$ \\
\hline Generic drug & $\begin{array}{l}\text { Requires } \\
\text { comprehensive } \\
\text { comparative } \\
\text { analytical } \\
\text { characterization }\end{array}$ & Not required & $\begin{array}{l}\text { Only bioequivalence } \\
\text { studies required. } \\
\text { Bioequivalence } \\
\text { studies could be } \\
\text { waived for certain } \\
\text { products }\end{array}$ & Not required & Not required & $\begin{array}{l}\text { Risk management plan } \\
\text { (EU only). } \\
\text { Pharmacovigilance } \\
\text { program/safety } \\
\text { monitoring }\end{array}$ \\
\hline
\end{tabular}

EU: Europe; MOA: Mechanism of action; PD: Pharmacodynamics; PK: Pharmacokinetics.

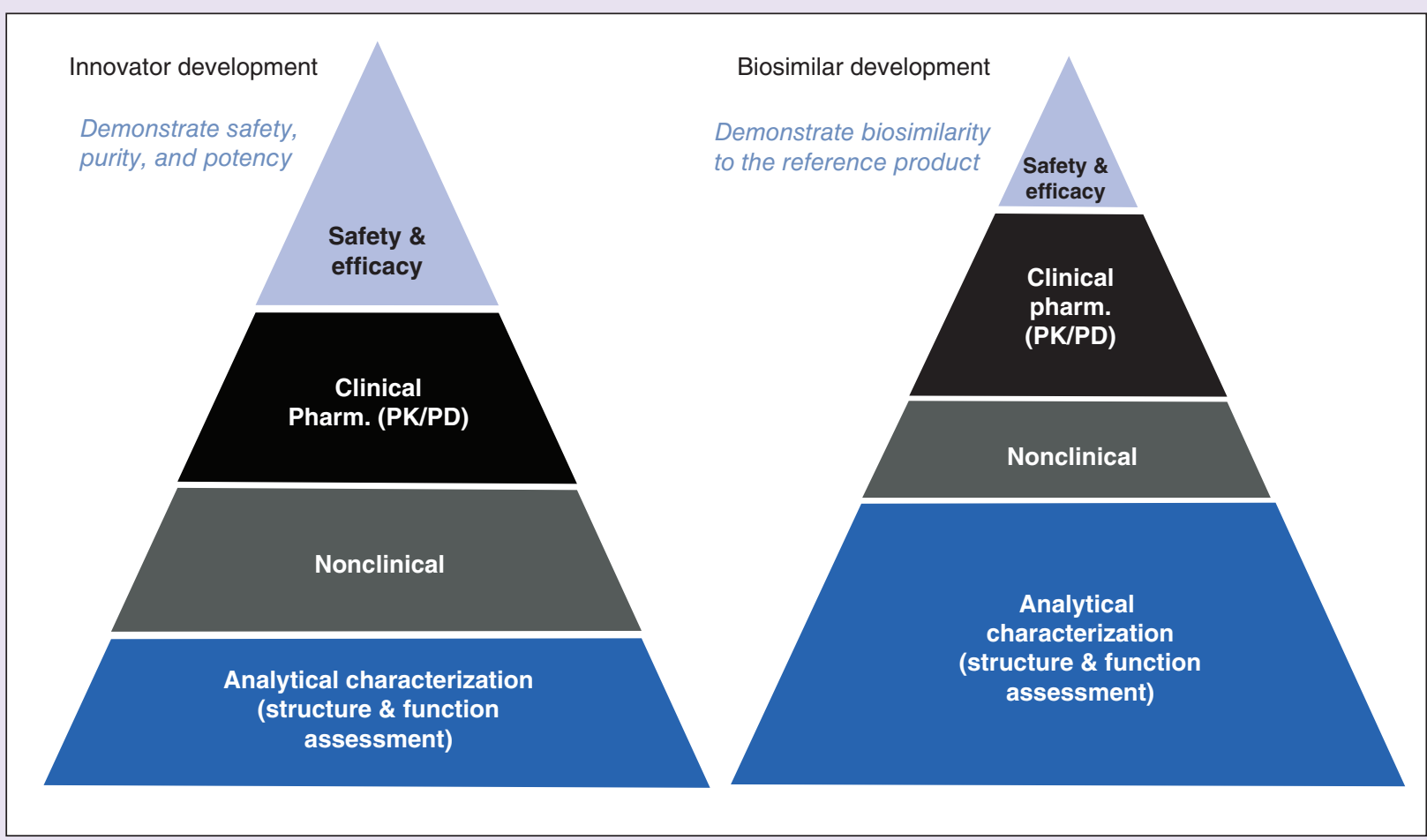

Figure 2. Development of biosimilars versus originator medicines.

Reproduced with permission from [15].

BLA: Biologic license application; PD: Pharmacodynamics; PK: Pharmacokinetics.

Biosimilar development: a stepwise approach to build a 'totality of evidence'

Rather than relying on discrete tests or studies, the development process for biosimilars focuses on building a totality of evidence (TOE) that together supports the similarity of the proposed biosimilar with the RP and includes a stepwise investigational approach that will help establish such similarity between the two products [10,22]. 
Table 3. Typical structural and in vitro functional assessment for a monoclonal antibody biosimilar.

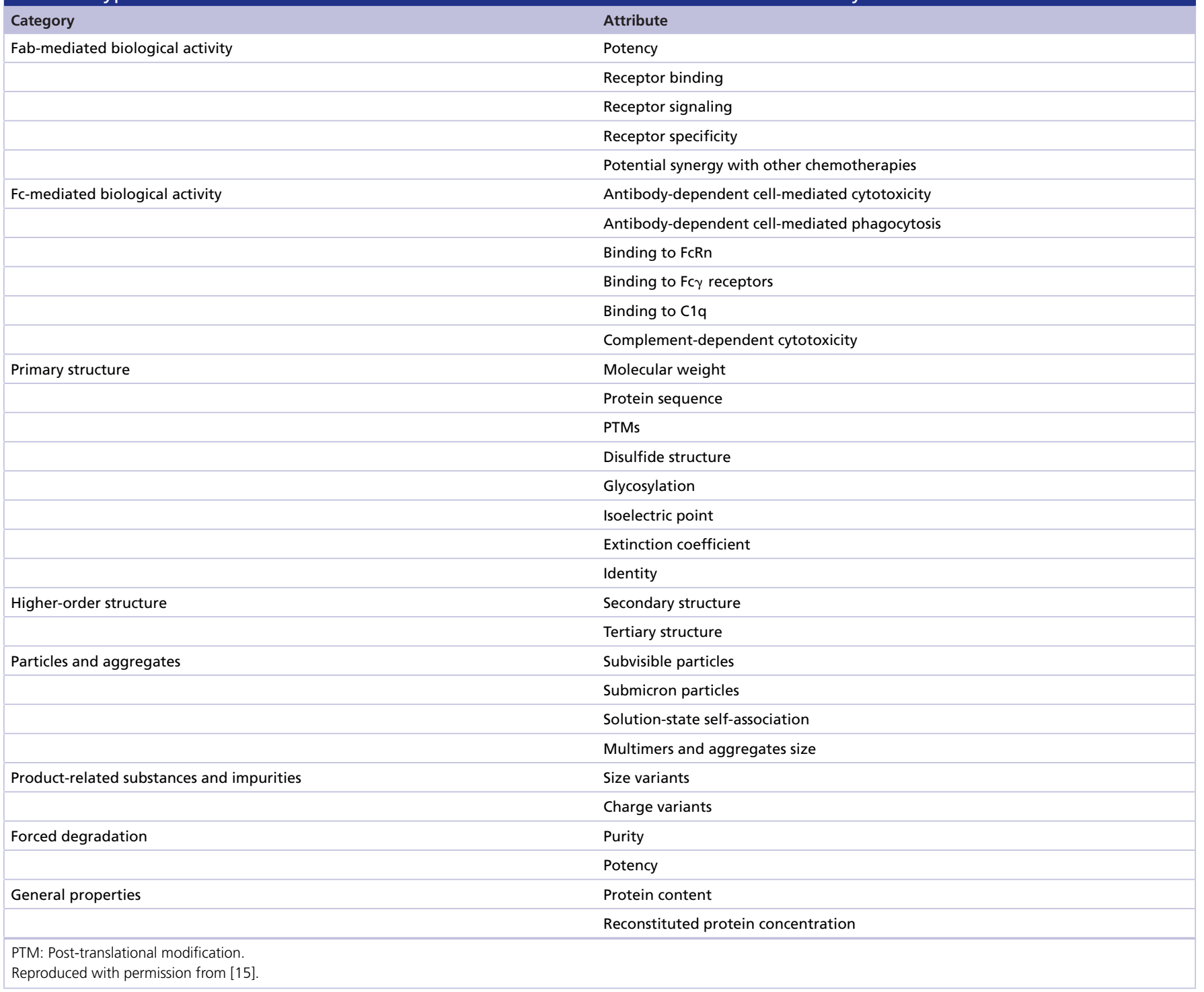

The stepwise approach begins with a comparative analytical characterization and a comprehensive functional and preclinical assessment of the proposed biosimilar followed by testing for clinical PK and PD similarity with the $\mathrm{RP}$ [23]. It is recommended that the stepwise approach to gathering evidence for the establishment of biosimilarity culminate in at least one comparative clinical study with the goal to confirm equivalence with respect to efficacy in a representative sensitive indication and, to assess the safety and risk of immunogenicity, thereby demonstrating no clinically meaningful differences. The patient population that is selected for Phase III evaluation should be sufficiently sensitive to detect potential clinical differences between the proposed biosimilar and the RP.

In general, regulatory approval of a proposed biosimilar can be attained only after its comparison with an RP that has been approved for use in the local territory. In other words, a biosimilar candidate being tested in the US should be compared with the RP that is approved in the US. Similarly, a biosimilar candidate being tested in the EU should be compared with the RP that is approved in the EU. However, both EMA and US FDA have moved toward global development programs that allow the use of foreign-sourced RPs in clinical studies, provided that there is sufficient, validated and documented scientific rationale to support this approach $[7,10,22]$. The establishment of such a 'scientific bridge' between the local RP and the foreign-sourced RP is based on comprehensive analytical similarity (structural and functional assessments, including a mechanism of action [MOA]) and clinical Phase I PK/PD studies of the proposed biosimilar against both the locally sourced RP and foreign-sourced RP. Using 
both comparators in early studies to establish the scientific bridge does not imply that comparators sourced from different regions are biosimilars of each other. The scientific bridge between the local RP and a foreign RP permits the use of a single comparator in the subsequent Phase III clinical study, thereby minimizing overall development costs. The final assessment of the adequacy of the bridging studies and the scientific justification of the comparisons is made by the regulatory authorities.

\section{Analytical characterization \& functional assessment}

Comprehensive structural and functional characterization of the proposed biosimilar constitutes the foundation for the biosimilar development program. The demonstration of biosimilarity begins with analytical assessment of the proposed biosimilar agent and its RP, and addresses all categories of product attributes necessary for demonstrating similarity $[10,16]$. This step includes a comprehensive array of complementary and orthogonal, in other words, statistically independent, analytical assessments that are used to identify any potential differences between the proposed biosimilar and its RP. This is important since such differences may potentially impact the pharmacologic properties, immunogenicity, clinical efficacy and/or safety of the biosimilar candidate. Demonstrating a high degree of structural and functional similarity between the proposed biosimilar and its RP is expected to provide greater assurance for the subsequent demonstration of clinical similarity between the products including helping facilitate extrapolation from a single indication that is tested clinically to all other approved indications of the RP where these are scientifically justified. Analytical testing typically includes assessments of primary and higher-order structure (including amino acid sequence, disulfide structure and glycan profile), biological activity and potential productand process-related impurities. There may be differences between two products, but presumably only the biosimilar product that is highly similar to the RP will be evaluated for clinical similarity.

The functional assessment of a proposed biosimilar includes an evaluation of its biological activity and MOAs. The goal is to gain confidence that the proposed biosimilar will have the same activity as its RP. Functional assessment of a mAb biosimilar candidate, for instance, focuses on the biological effects of the targeted antigen. Here, functions associated with binding of the proposed $\mathrm{mAb}$ biosimilar to the antigen-binding ( $\mathrm{Fab}$ ) region and its complement-binding $(\mathrm{Fc})$ region become important (Figure 3) [24,25]. Target binding and antibody neutralization are typically mediated via the Fab region. Fab-mediated functions also affect immunogenicity since crossreactivity and immunoreactivity occur via this region [25]. The Fc region, in contrast, is important for complement interactions as well as binding to neonatal $F_{c}\left(F_{c} R n\right)$ and $F_{c} \gamma$ receptors. Binding in this region can influence product PK characteristics. In addition, Fc $\gamma$ binding mediates antibody-dependent cell-mediated cytotoxicity (ADCC) and antibody-dependent cellular phagocytosis, both of which may contribute to therapeutic benefits [25]. A thorough functional assessment should include an evaluation of these functions. Table 3 provides a list of the many structural and functional assessments that can be involved in the testing of a proposed biosimilar.

\section{Preclinical assessments}

Establishment of analytical (structural and functional) similarity is followed by preclinical assessments. These studies may be required to fully assess toxicity when uncertainties persist even after completion of extensive structural and functional characterization. Preclinical testing may include animal studies to assess toxicology, toxicokinetics and PK evaluations. Nevertheless, animal studies may be skipped if rigorous structural and functional comparisons show minimal or no differences between the proposed biosimilar and the RP. In this case, there would be a strong justification to follow a more selective and targeted approach to clinical testing [10].

It is also important to fully evaluate a proposed biosimilar based on the specific MOA of the RP, if known. The evaluation of a proposed biosimilar of trastuzumab, for example, should include specific assessments of mechanisms that are known to lead to tumor cell death and/or tumor cell stasis, including the activation of ADCC, inhibition of extracellular domain cleavage, the inhibition or blocking of HER2-mediated intracellular signaling, inhibition of angiogenesis and decreased DNA repair following exposure to chemotherapeutic agents [26-28]. Based on the same thinking, the evaluation of a proposed biosimilar to an anti-CD20 antibody such as rituximab would include assessments of immune-mediated effects on complement-dependent cytotoxicity and ADCC as well as the MOA based on direct effects on cell signaling pathways and cell membranes post-CD20 binding [29].

\section{Clinical development}

After analytical similarity (structural and functional) has been confirmed, the next step is the assessment of its clinical similarity. This process begins with an assessment of the clinical pharmacologic (PK/PD) profile of the 


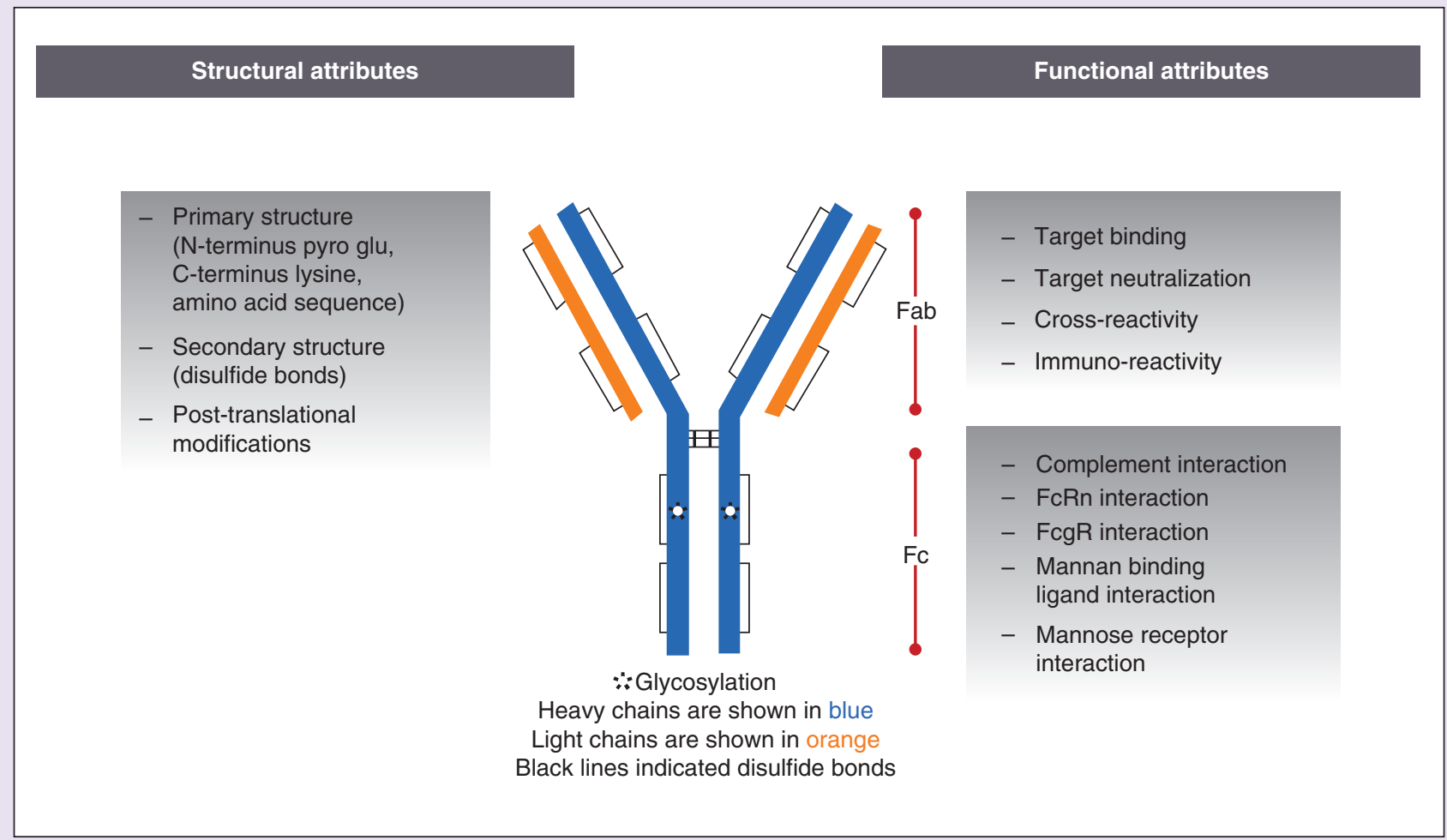

Figure 3. Critical quality attributes of a monoclonal antibody biosimilar. Adapted from [24]; https://creativecommons.org/licenses/by-nc/4.0/

proposed biosimilar. Similarity of PK/PD is assessed in a Phase I study which is typically conducted in healthy subjects $[10,30,31]$. Healthy subjects are included in PK/PD studies to ensure that the study population is homogenous and immunocompetent, allowing for a sensitive comparison between the proposed biosimilar and the RP. In these studies, PK bioequivalence is considered to have been established when the two-sided $90 \%$ CI of the geometric mean ratio of $\mathrm{PK}$ values between the proposed biosimilar and the RP falls within a prespecified bioequivalence margin of $80-125 \%$ for overall exposure [22]. It should be noted that the prespecified bioequivalence margin does not denote that the point estimates of the functionality (e.g., $\mathrm{C}_{\max }$ and $\mathrm{AUC}_{\mathrm{inf}}$ for $\mathrm{PK}$ assessments) of the biosimilar may vary from 80 to $125 \%$ of the RP, but rather that both sides of the $90 \%$ CI must be fully contained within this equivalence margin to meet the standard for bioequivalence (Figure 4).

Phase I PK/PD studies include PK assessments (drug absorption, distribution, metabolism and excretion) as well as PD assessments (pharmacologic effects of drugs on the body). While PD studies can provide useful additional evidence of drug function, these can be assessed only when a suitable PD marker is available. The $\mathrm{PK} / \mathrm{PD}$ assessments form an integral and critical part of the TOE demonstrating similarity between a proposed biosimilar and its RP. Evidence from these studies inform the design of subsequent clinical trials of efficacy and safety. They are also useful in providing scientific justification for extrapolation to indications that are not actively evaluated in the prospective clinical trial of the biosimilar. After structural, functional and clinical PK similarity of the biosimilar with the RP has been shown, the clinical program can directly move to a Phase III confirmatory trial. Phase II studies are not required for biosimilar development.

The demonstration of clinical similarity in a Phase III comparative study is the final step for the demonstration of biosimilarity between the proposed biosimilar and its RP. For reasons described above, efficacy studies should be carefully planned and conducted in patient populations that are expected to be sensitive enough to detect clinically meaningful differences between products [10]. The overall goal of the head-to-head trial is to demonstrate that the biosimilar candidate has neither decreased nor increased efficacy compared with the originator product and that it also has a similar safety profile. In its simplest form, such a trial is based on the null hypothesis, with a prespecified 


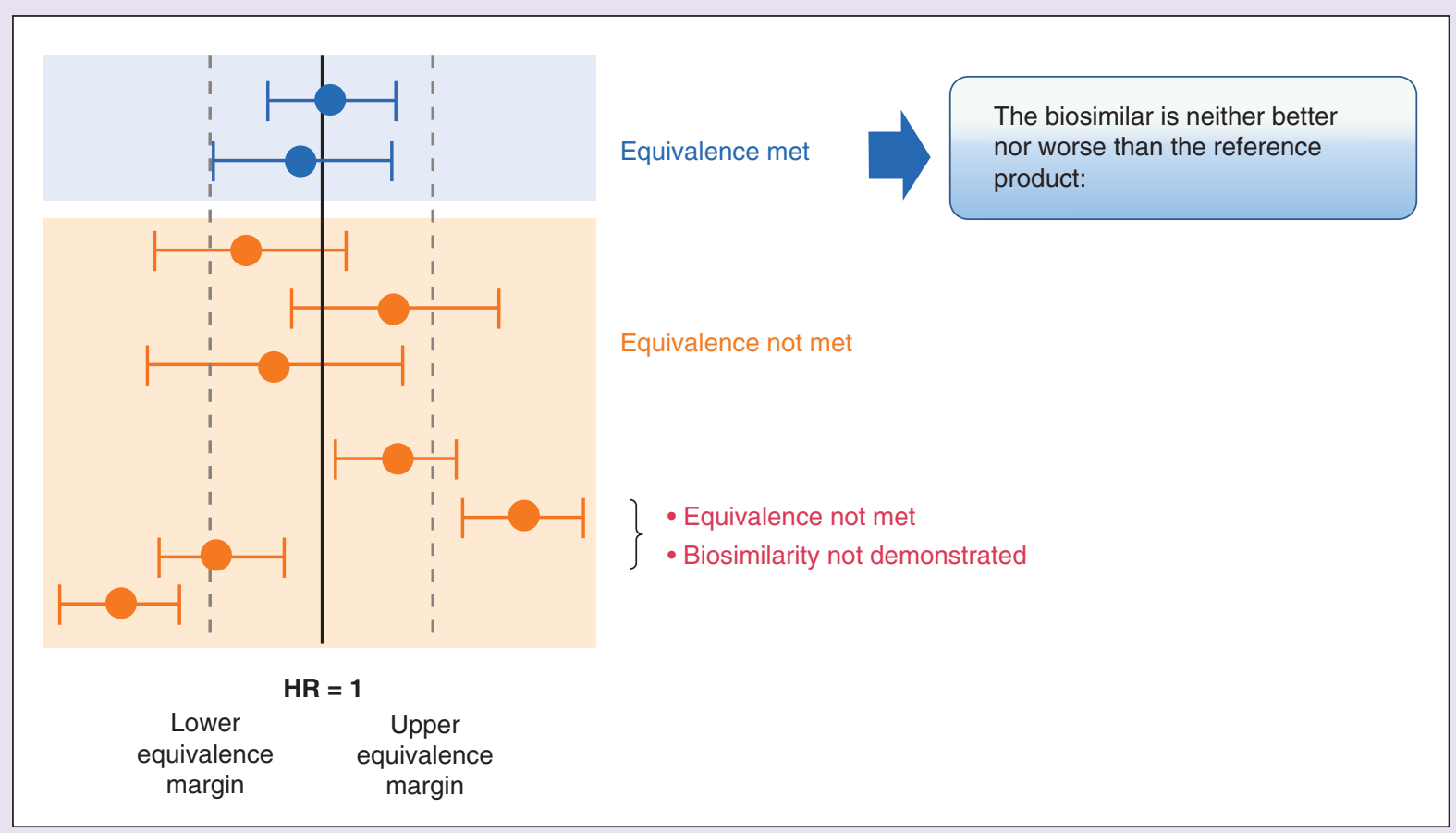

Figure 4. Clinical similarity based on a predetermined equivalence margin.

equivalence margin and a two-sided test that demonstrates that the efficacy of the proposed biosimilar lies within these margins [10]. The equivalence margins should be scientifically justified and be adequate enough to allow for the detection of any clinically meaningful difference in efficacy, should such a difference exist. In general, 90\% CIs for equivalence studies are recommended in the guidelines for assessing PK equivalence, whereas 95\% CIs are recommended for assessing clinical equivalence $[32,33]$. The efficacy end point could be that of clinical benefit, or alternatively, a meaningful surrogate for efficacy. It is recommended that safety and efficacy of the biosimilar candidate be assessed in the same study. The caveat here is that the selected study population be sensitive enough to evaluate specific safety measures. Ideally, this would be a population in which the investigational product is used as monotherapy.

The use of surrogate end points as efficacy measures may play a crucial role in clinical trials involving biosimilars. It is well known that overall survival (OS), for example, is a gold standard in proving clinical benefit in oncology trials. However, OS is not a realistic primary end point in the clinical evaluation of biosimilars as the goal here is not to prove or re-establish inherent clinical benefit but to detect and determine if there are differences between the clinical effects of the biosimilar candidate versus the RP. The key here is selecting an appropriate end point, which should be sensitive enough to detect a difference in activity if one exists. It is proposed that response rate and complete response can serve as suitable and adequate end points in clinical assessments of biosimilars in metastatic disease [34]. Furthermore, since these are comparator-controlled trials between two presumably very similar products, it may be appropriate to use the ratio of the overall response rates (ORRs) as the primary end point. The closer this ratio is to 1 , the smaller the difference in response rates between the two products (test and comparator), and thus greater the similarity between the products.

In addition to the response rate and complete response discussed above, other surrogate end points can play an important role in gaining key information from oncology trials. In the case of neoadjuvant breast cancer trials, for example, pathologic complete response (pCR) has been proposed as one such outcome measure [34,35]. A pCR is defined as the absence of residual invasive disease in the breast and axillary lymph nodes at the completion of neoadjuvant treatment. Published evidence indicates that patients who achieve pCR with neoadjuvant therapy tend to have a better prognosis than patients who had residual invasive disease at the end of treatment [36]. Patients who achieved pCR have been reported to have $50 \%$ reduced risk of reoccurrence of distant disease and $36 \%$ 
improvement in OS when compared with those who did not achieve pCR. Patients with more aggressive cancer subtypes, such as hormone receptor-negative, HER2-positive and triple-negative breast cancer, have been reported to experience a $75 \%$ improvement in OS. A meta-analysis of results from trastuzumab clinical trials found that in HER2-positive breast cancer, total pCR is a more sensitive end point than ORR [37]. Thus, documentation of pCR may be a sensitive surrogate end point for the demonstration of similarity in biosimilar trials comparing a proposed biosimilar and its RP in breast cancer.

\section{Statistical considerations in clinical study design}

To reiterate, the overall goal of the Phase III clinical development program for a biosimilar is not to establish efficacy per se but to demonstrate similarity between the comparators, in this case, the proposed biosimilar and its RP. The goal is also to show that the two products have a similar safety and immunogenicity profile. This need to demonstrate lack of clinically meaningful differences between the comparators in measures of efficacy and safety drives the design of the clinical study, including the selection of the patient population, study end points (surrogate or otherwise) and the statistical methods used.

A final consideration in demonstrating clinical similarity of a biosimilar with its RP is the testing of statistical equivalence of the primary end point. The equivalence test compares the $\mathrm{CI}$ of the observed treatment difference within a predefined equivalence margin (Figure 4). Most biosimilar studies use a two-sided statistical test designed to demonstrate that the proposed biosimilar is neither inferior nor superior to the RP based on a prespecified margin. The equivalence margin is determined based on an estimated effect size derived from a combination of historical data and other relevant clinical and statistical considerations. Since these studies are designed to detect differences between a biosimilar and its RP, two very similar products, results are generally expressed as the risk ratio (RR) or risk difference (RD) in efficacy between the two. Clinical equivalence is established based on a predetermined two-sided $90 \%[5]$ or $95 \%$ CI [32,33] of the RR or RD since the studies are designed to determine both noninferiority and nonsuperiority of the proposed biosimilar. If the $\mathrm{CI}$ of the RR or RD is contained within the equivalence margin, then the two products are considered clinically similar (Figure 4).

Patient populations are carefully selected to maximize the probability of detecting any clinically meaningful differences between the proposed biosimilar and the RP, and prespecified equivalence margins are determined based on the sum of evidence available for the RP. For example, in breast cancer studies, patients with early/neoadjuvant disease provide for a more sensitive biosimilarity assessment as compared with patients with more advanced or metastatic disease. In neoadjuvant patient populations, the achievement of pCR correlates with long-term survival, whereas ORR, the commonly used end point in metastatic disease, is associated with a larger uncertainty in long-term efficacy outcomes [37].

A few Phase III clinical studies have included a single switch in their study designs. These studies provide important information regarding the efficacy, safety and especially immunogenicity after a single switch from the $\mathrm{RP}$ to the proposed biosimilar and may alleviate some of the safety and immunogenicity concerns in this regard. An example would be the randomized, multicenter, double-blind active-controlled Phase III LILAC study in which the biosimilar product ABP 980 was compared with the reference trastuzumab (Herceptin ${ }^{\circledR}$ ) in adult women with HER2-positive early breast cancer [38]. After the neoadjuvant treatment and subsequent surgery, patients continued to the adjuvant phase on investigational product every 3 weeks for up to 1 year. This study included a switch arm in which patients who were randomized to trastuzumab during the neoadjuvant phase were rerandomized to remain on RP or switch to ABP 980 during the adjuvant phase, whereas patients randomized to ABP 980 in the neoadjuvant phase continued receiving ABP 980. Results confirmed that safety and immunogenicity were similar in patients who switched and in those who continued to receive trastuzumab as adjuvant therapy. Switching studies also provide an opportunity to gain insights on comparative efficacy and potential safety concerns in a more 'real-world'-like setting, given that some patients are likely to be switched from an originator RP to a biosimilar. However, physicians must be cautious when switching to or between biosimilars and should keep track of which biologic is being used. Otherwise multiple switches may inadvertently occur, increasing the risk for immunogenicity reactions.

\section{Assessment of immunogenicity}

The assessment of immunogenicity is an important aspect for obtaining regulatory approval for biosimilars since minor variants introduced during biosimilar manufacturing could potentially result in differing immunogenicity profiles of biosimilars versus RPs. Additionally, the development of antidrug antibodies (ADAs) with treatment 
may result in a decreased therapeutic response by decreasing the half-life of the drug or, in rare cases, by neutralizing the effects of the drug [39]. Thus, the demonstration that there is no meaningful difference in immunogenicity between the proposed biosimilar and the RP is an important part of the step-wise building of the TOE to support biosimilarity. Nonclinical methods of assessing immunogenicity are not sufficient to predict potential immunogenicity in patients; therefore, a biosimilar development program should include at least one clinical study that allows for a comparison of the immunogenicity between the biosimilar candidate and the RP.

The immunogenicity potential of products is determined by measuring binding antibodies and neutralizing antibodies in treated patients using state-of-the-art assays. Assays used in the measurement of ADAs have seen dramatic advances in the last two decades such that more sensitive and specific detection of antibodies is now possible, including in the presence of significant serum drug levels [40]. It should be noted that the improved ability to detect serum antibodies may lead, in some cases, to the misperception of somewhat higher levels of ADAs in the newer biosimilar trials than those observed in earlier RP trials [41]. Another point to note is that increased assay sensitivity may also lead to potentially false-positive results, including in patients who are naive to drug and who have pre-existing ADAs prior to drug exposure in the current trial. Care should therefore be taken to note the sensitivity of ADA assays used in different trials when interpreting results across trials.

Whereas for many mAbs (originator and biosimilar), immunogenicity is not a concern, there may be other mAbs where the development of ADAs could impact the PK, leading to differences in drug exposure. This may not be a concern if these differences are similarly impacted for both the proposed biosimilar and the RP; however, any differences may lead to differences in efficacy and safety between the two, thereby impacting biosimilarity.

\section{Biosimilars in combination treatments}

Optimal treatment of patients with cancer generally involves combination therapy. It is thus important to study the use of biosimilars in this setting and to evaluate the realistic expectation of whether the proposed biosimilar could replace the originator product (reference biologic) in clinical practice. As an example, the development of resistance to trastuzumab is a known occurrence. The addition of lapatinib to trastuzumab in combination therapy has been shown to extend disease-free survival in patients with metastatic breast cancer (MBC), resulting in improved progression-free survival and clinical benefit rate [42]. In addition, treatment with a combination of trastuzumab and pertuzumab - a mAb that binds to a different antigen epitope and acts by disrupting HER2 dimerization, an essential prerequisite for HER2 activation - has been shown to be well tolerated and to provide clinical benefit beyond progression on prior trastuzumab therapy in MBC [43,44]. With the approval of trastuzumab biosimilars, it may be possible to replace trastuzumab with its biosimilar in all treatment protocols, including in combination therapies, similar to what was done in the recent GeparX study, where the trastuzumab biosimilar ABP 980 was used as part of combination therapy [45]. If the biosimilar has been shown to be highly similar to trastuzumab based on analytical, functional (including mechanistic), preclinical and clinical (PK, efficacy and safety) assessments; this replacement would be expected to provide similar outcomes as the originator trastuzumab in monotherapy and in combination therapies. However, regulators may still require additional data, including dose ranging, efficacy and safety studies.

\section{Biosimilars \& the concept of extrapolation}

When used in the context of biosimilars, extrapolation refers to the process of obtaining approval for use in a clinical indication other than that tested in a Phase III comparative trial of biosimilars. Here, extrapolation refers to the extension of indications from the one tested in a biosimilar clinical trial to any or all other indications approved for use of the originator RP even though new biosimilar trials are not conducted to directly support those other indications. The abbreviated regulatory pathway allows for a scientific extension or extrapolation of indications based on the extensive demonstration of structural, preclinical and limited clinical similarity of the biosimilar with the RP as well as scientific understandings of the MOA, potential differences in PK or biodistribution and evaluation of potential additional risks, such as immunogenicity (Figure 5). Although there is growing acceptance of biosimilars and their usefulness as alternatives to originator biologics, there is still some hesitation among clinicians and other HCPs regarding their use in clinical practice for indications that are based on extrapolation of data from a clinical trial conducted in a different patient population [46].

Both the FDA and EMA guidelines state that extrapolation of indications can be accepted provided that adequate scientific justification is available $[10,11]$. Weise $e t a l$. have reviewed the scientific principles underlying extrapolation and identified the following factors as key: there must be a high degree of similarity in the physicochemical structure 


\section{Knowledge of the reference product}

\section{Biosimilar development}

Demonstrate biosimilarity to the reference product

Clinical (saf \& eff)

Totality of evidence

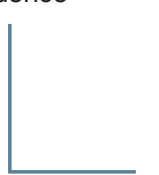

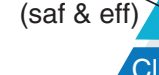

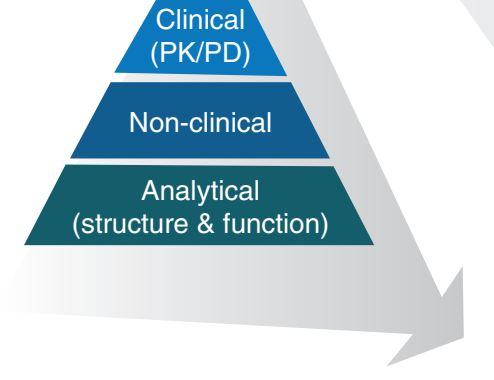

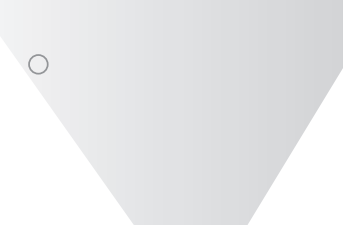

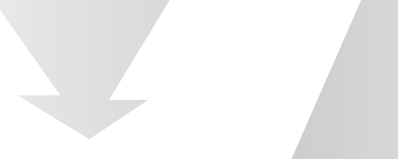

Extrapolation
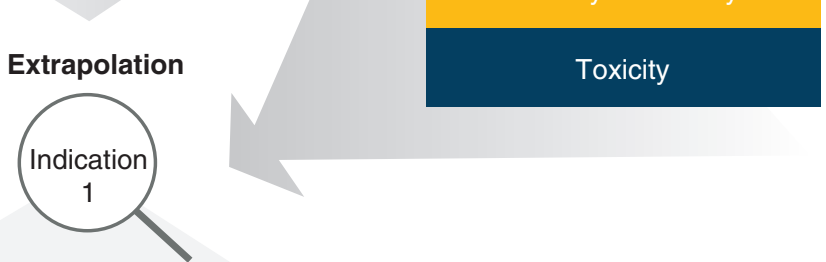

Mechanism of action

PK

Immunogenicity

Efficacy and safety

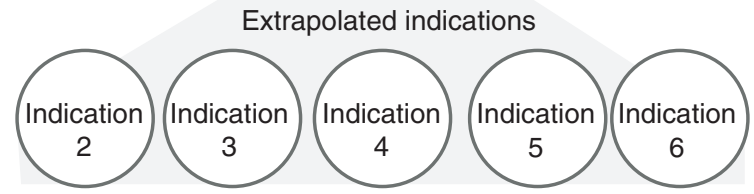

Figure 5. Extrapolation of indications for a proposed biosimilar is based on the knowledge of the reference product and scientific justification.

Eff: Efficacy; PD: Pharmacodynamics; PK: Pharmacokinetics; Saf: Safety.

and biological activity between the biosimilar and the RP; the PK profiles of the two agents must be comparable; the MOA involved in the indication tested and in the extrapolated indication(s) should be addressed; the two agents should have comparable PD activities (when PD is measured) and the safety and immunogenicity profiles of the two agents must be comparable in patient populations that will be targeted for the indicated therapies [47]. Here, it is important to add that extrapolation is determined based on the overall TOE and not on clinical assessments alone. If all the above conditions are met and the study population in the evaluated indication is sensitive enough to detect clinically meaningful differences, then the proposed biosimilar may be expected to have similar efficacy and safety in all other approved indications of the RP. In this case, extrapolation is considered to be scientifically justified.

While it may be assumed that in most instances a biosimilar can be safely extrapolated to indications that share a common MOA, there may be exceptions when this is justifiable to only some of the approved indications of the RP. For example, the efficacy of rituximab, an anti-CD20 mAb, in non-Hodgkin lymphoma, is thought to be due to its direct signaling of apoptosis independent of immune effector mechanisms, whereas its efficacy in rheumatoid arthritis is believed to be largely due to complement activation and cell-mediated toxicity [29,48]. In this case, separate biosimilar trials in at least two different study populations may be needed to independently extrapolate biosimilar indications mediated via these different MOAs and potential extrapolation is available with demonstrations of functional equivalence of all MOAs. It should be noted, however, that extrapolation is not allowable for indications of the RP that are still under regulatory exclusivity. Additionally, whether extrapolation is granted or not is at the discretion of regulators. 


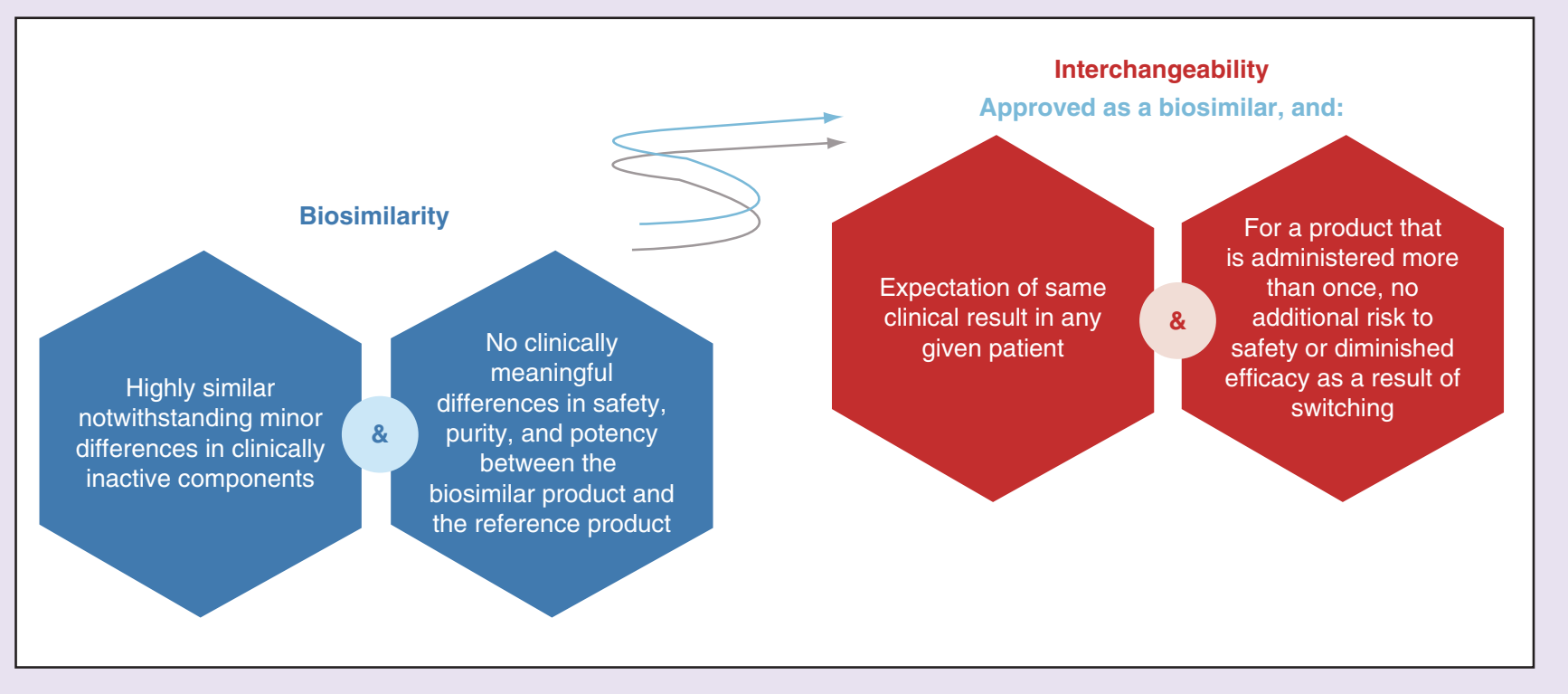

Figure 6. US FDA standards for an interchangeability designation.

\section{Are biosimilars \& RPs interchangeable?}

With the advent of biosimilars, clinicians are likely to face two different decisions. First, should treatment be initiated with a biosimilar and second, can the patient safely be transitioned from an RP to a biosimilar? Based on the law and FDA draft guidance on interchangeability [49,50], a biosimilar designated as interchangeable 'may be substituted for the RP without the intervention of the HCP who prescribed the reference product' as permitted by state law. In order to meet the legal standard of interchangeability in the US (Figure 6), there must be sufficient evidence supporting biosimilarity and an evidence-based expectation that the biosimilar 'can be expected to produce the same clinical result as the RP in any given patient and, if the biological product is administered more than once to an individual, the risk in terms of safety or diminished efficacy of alternating or switching between the use of the biological product and the RP is not greater than the risk of using the RP without such alternation or switch' [50]. If this standard is met, a biosimilar may be substituted for the RP at the pharmacy 'without the intervention of the prescribing healthcare provider' to the extent permitted by state law. The FDA guidance on interchangeability suggests that clinical studies designed to support interchangeability should include at least three switches between the biosimilar and RP [50]. With respect to oncology products, an interchangeability designation and pharmacy substitution pursuant to state law, is not expected to have much effect because most biologics for oncologic indications are administered in a clinical setting and are not dispensed at a retail pharmacy. To the best of our knowledge, there are only three studies that have evaluated interchangeability based on such a study design. These include studies with two mAbs (etanercept, infliximab) and one study with filgrastim [51-54]. In contrast to FDA, the EMA itself does not evaluate whether biosimilars and RPs are considered interchangeable. Rather, individual member states have the authority to make decisions about pharmacy substitution for biologics and most member states do not allow such practice [55], and in general they do not support pharmacy substitution of biologics. Of note, the FDA has not granted the 'interchangeable' designation to any biosimilar agent at this time. The EU does not have a specific requirement or recommendation for interchangeability. Although biosimilars are approved centrally by the EMA, each individual nation's regulatory authority establishes substitution policies in their domain.

\section{Naming \& pharmacovigilance}

Other considerations for the successful adoption and use of biosimilars include naming criteria and safety monitoring or pharmacovigilance. The FDA has issued guidance that discusses the use of distinguishable names by adding a unique four-letter suffix to the 'core name' (typically similar to the international nonproprietary name, or INN) for each biologic product whether it is an originator or a biosimilar [56]. It is important to recall here that approval 
for use of a particular biosimilar product in some indications will be based on extrapolation of evidence in other indication(s) and that each biosimilar agent may not be approved for all indications as the originator RP. Therefore, use of distinguishable names for each biosimilar is vital to ensure that the right medication has been dispensed to ensure optimal patient outcomes. This is an important consideration when clinical practice decisions have to be made regarding drug selection, and the possibility of inadvertent substitution of a drug by a pharmacist because of a lack of specificity in product name must be clearly avoided. This is especially important when products have not been approved as interchangeable (only in the USA) and it is unknown if switching some products has increased immunogenicity risks. The adoption of distinguishable names for biosimilars is also important from a pharmacovigilance perspective and will serve to ensure that specific adverse events are correctly attributed to the appropriate product/manufacturer. A robust risk management plan thus forms an integral part of the overall biosimilar program. Accurate reporting by physicians and pharmacists of the product prescribed and dispensed, including the product name and any distinguishing suffix, is critical to patient safety.

Unlike in the US, there is currently no specific guidance regarding the naming of biosimilars in the EU or related to the addition of a unique four-letter suffix to the international nonproprietary name. For biosimilars and indeed for all biologics, the prescriber in the EU must document not only the trade name but also the batch number of the product [57]. This is not currently done consistently in clinical practice and directly impacts the ability to identify a specific product that may be responsible for an adverse event. The importance of pharmacovigilance and the need for a robust pharmacovigilance plan is nonetheless recognized and is expected to be part of the submission package.

\section{Biosimilars in oncology}

While several biosimilars are now in clinical development, many are marketed or awaiting market introduction following approval by one or more regulatory agencies. Table 4 lists the biosimilars approved for use in the treatment of various cancers [24].

Each biosimilar is clearly a unique product made using a unique cell line and having its own specific manufacturing process. Each developer has many decisions to make, including making their own cell line and developing their own manufacturing process. In addition, the data required to support the degree of similarity, including clinical trial data, will differ between biosimilars. Therefore, when choosing which biosimilar to use, the clinician must consider differences in approved indications, presentations, study design and supporting data, as well as patient support services. While regulatory agencies mandate that a proposed biosimilar be compared with the RP, they do not require any comparison of one biosimilar with another. Therefore, clinicians should be cautious when switching between biosimilars. This is especially important when considering that, unlike G-CSF or erythropoietin biosimilars, it typically takes time to see therapeutic results and any adverse events with $\mathrm{mAbs}$ for oncologic diseases. In addition, as discussed in preceding sections, the production of complex biologic agents in living cells can be influenced by multiple factors such as changes in cell lines, reagents or changes in the manufacturing process, including changes in equipment. Such changes can introduce minor modifications, which may over time adversely affect stability, efficacy, safety and/or immunogenicity. Therefore, all the precautions and vigilance that are used to monitor originator biologics must also be used to monitor biosimilars and ensure that no clinically meaningful change occurs over the life cycle of the product. Finally, as with any new product, clinical trial data alone will be insufficient to fully assess the long-term safety of biosimilars. A comprehensive understanding of the safety profile of a biosimilar will also require the implementation of rigorous pharmacovigilance programs and review of real-world evidence to ensure ongoing safety and clinical efficacy.

\section{Future perspective}

Regulatory approval, of course, is only one step in the process and does not lead automatically to the integration of a new agent into clinical practice guidelines and pathways and subsequently into clinical practice. We have already seen that there is a need for full transparency of reporting of both preclinical and clinical data including safety and efficacy studies in order for biosimilar agents to be embraced by the clinical community. Clinical practice guideline panels have been reluctant to recommend the use of biosimilars when supporting data provided to the FDA at the time of regulatory approval are not publicly available either through presentation to a Drug Advisory Panel or by publication in the peer-reviewed medical literature. It will be important that the data considered by the FDA in approving biosimilars be available for full review by clinicians, patients and developers of evidence-based clinical practice guidelines and pathways. 
Table 4. Biosimilars for use in oncology: recommended for approval or approved in the EU and or US.

\begin{tabular}{|c|c|c|c|}
\hline Biosimilar & Active substance & Region & Marketing Authorization Holder/Manufacturer \\
\hline \multicolumn{4}{|l|}{ Erythropoiesis-stimulating agents } \\
\hline Abseamed $^{\circledR}$ & Epoetin alfa & EU & Medice Arzneimittel Pütter \\
\hline Binocrit $^{\circledR}$ & Epoetin alfa & EU & Sandoz \\
\hline Epoetin alfa Hexal ${ }^{\circledR}$ & Epoetin alfa & EU & Hexal/Sandoz \\
\hline Retacrit $^{\text {TM }}$ & Epoetin zeta & EU & Hospira \\
\hline Retacrit $^{\top M}$ & Epoetin alfa-epbx & US & Hospira \\
\hline Silapo ${ }^{\circledR}$ & Epoetin zeta & EU & Stada Arzneimittel \\
\hline \multicolumn{4}{|c|}{ Granulocyte colony-stimulating factors } \\
\hline Fulphila $^{\circledR}$ & Pegfilgratim-jmdb & US & Mylan \\
\hline Fulphila ${ }^{\circledR}$ & Pegfilgrastim & EU & Mylan \\
\hline Udenyca $^{T M}$ & Pegfilgrastim & EU & ERA Consulting/Coherus Biosciences \\
\hline Udenyca $^{T M}$ & Pegfilgrastim-cbqv & US & Coherus Biosciences \\
\hline Pelgraz $^{\circledR}$ & Pegfilgrastim & EU & Accord Healthcare \\
\hline Ziextenzo ${ }^{\circledR}$ & Pegfilgrastim & EU & Sandoz \\
\hline Pelmeg ${ }^{\circledR}$ & Pegfilgrastim & EU & Cinfa Biotech S.L. \\
\hline Accofil $^{\circledR}$ & Filgrastim & EU & Accord Healthcare \\
\hline Biograstim $^{\dagger}$ & Filgrastim & EU & AbZ-Pharma/Merckle Biotec \\
\hline Filgrastim Hexal ${ }^{\circledR}$ & Filgrastim & EU & Hexal/Sandoz \\
\hline Filgrastim ratiopharm ${ }^{\dagger}$ & Filgrastim & EU & Ratiopharm/Merckle Biotech \\
\hline Grastofil $^{\circledR}$ & Filgrastim & EU & Apotex \\
\hline Nivestim $^{T M}$ & Filgrastim & EU & Pfizer/Hospira \\
\hline Nivestym $^{T M}$ & Filgrastim-aafi & US & Pfizer/Hospira \\
\hline Ratiograstim ${ }^{\circledR}$ & Filgrastim & EU & Ratiopharm \\
\hline Tevagrastim $^{\circledR}$ & Filgrastim & EU & Teva \\
\hline Zarzio $^{\circledR}$ & Filgrastim & EU & Sandoz \\
\hline $\operatorname{Zarxio}^{\circledR}$ & Filgrastim-sndz & US & Sandoz \\
\hline \multicolumn{4}{|l|}{ mAbs } \\
\hline Truxima $^{T M} \ddagger$ & Rituximab & EU & Celltrion \\
\hline Truxima $^{T M} \ddagger$ & Rituximab-abbs & US & Celltrion \\
\hline Rituzena (previously Tuxella) ${ }^{\ddagger}$ & Rituximab & EU & Celltrion \\
\hline Blitzima $^{\ddagger}$ & Rituximab & EU & Celltrion \\
\hline Ritemvia $^{\ddagger}$ & Rituximab & EU & Celltrion \\
\hline Rixathon ${ }^{\circledR \S}$ & Rituximab & EU & Sandoz \\
\hline Riximyo ${ }^{\circledR \S}$ & Rituximab & EU & Sandoz \\
\hline KANJINTI ${ }^{T M}$ & Trastuzumab & EU & Amgen \\
\hline Herzuma $^{\circledR}$ & Trastuzumab & EU & Celltrion \\
\hline Herzuma $^{\circledR}$ & Trastuzumab-pkrb & US & Celltrion and Teva \\
\hline Ontruzant ${ }^{\circledR}$ & Trastuzumab & EU & Samsung Bioepis \\
\hline Ontruzant ${ }^{\circledR}$ & Trastuzumab-dttb & US & Samsung Bioepis \\
\hline Ogivri $^{\mathrm{TM}}$ & Trastuzumab & EU & Mylan \\
\hline Ogivri $^{T M}$ & Trastuzumab-dkst & US & Mylan \\
\hline Trazimera $^{T M}$ & Trastuzumab & EU & Pfizer \\
\hline MVASI $^{\text {TM }}$ & Bevacizumab & EU & Amgen \\
\hline MVASI $^{\text {TM }}$ & Bevacizumab-awwb & US & Amgen \\
\hline Zirabev $^{\mathbb{I}^{\top M}}$ & Bevacizumab & EU & Pfizer \\
\hline \multicolumn{4}{|c|}{$\begin{array}{l}\text { †Withdrawn; same product as Ratiograstim. } \\
\text { ¥Rituximab biosimilar products with multiple distinct brand names based on separate regulatory approvals received by the same marketer (Celltrion); each product has a slightly } \\
\text { different authorization or indications profile. } \\
\text { \$Rituximab biosimilar products with multiple distinct brand names based on separate regulatory approvals received by the same marketer (Sandoz); each product has a slightly } \\
\text { different authorization or indications profile. } \\
\text { I From: www.pfizer.com/news/press-release/press-release-detail/pfizer_receives_european_approval_for_zirabev_bevacizumab_a_biosimilar_to_avastin } \\
\text { Source: US FDA and EMA. } \\
\text { mAbs: Monoclonal antibodies. }\end{array}$} \\
\hline
\end{tabular}


From a practical perspective, there continues to be some hesitation among clinicians to use biosimilars to their fullest extent $[58,59]$. While the relative newness of this category is likely a major contributing factor to this reluctance, other factors may additionally contribute to this hesitancy. In a recent survey of specialty physicians in the US, many respondents expressed concerns related to the safety of biosimilars. While dermatologists and rheumatologists expressed the most concern, slightly more medical oncologists (34\%) versus hematology oncologists (28.5\%) had safety concerns [46]. This highlights the need for education and training in this regard. Furthermore, physicians and patients alike appear uncertain about concepts such as extrapolation, which is unique to biosimilars. An understanding that extrapolation is based on the TOE of a proposed biosimilar in comparison with its RP rather than on clinical evidence related to any one indication may help physicians understand the scientific basis of extrapolation. The physician perception of adopting a biosimilar might also be reinforced by having a comparative clinical study in a curable setting, in other words, in early breast cancer versus MBC; however, it should be underscored that a TOE indicating that the biosimilar product is highly similar to the RP provides the best assurance of similar efficacy, safety and immunogenicity in all approved indications of the RP.

Major professional societies, such as the American Society of Clinical Oncology (ASCO) and the European Society of Medical Oncology (ESMO), are actively involved in monitoring developments and providing guidance on the use of biosimilars in oncology. American Society of Clinical Oncology recently (April 2018) issued a statement offering guidance on the safety and efficacy of biosimilars, issues of interchangeability, switching and substitution; naming, labeling, regulatory considerations; the value of biosimilars; and prescriber and patient education [1]. In it, they note that the 'appropriate incorporation of biosimilars into practice is left largely to clinical experience and judgment' and emphasize the importance of developing postmarket evidence as a means of gathering additional data regarding risks and benefits of switching from originators to biosimilars and between biosimilars. In Europe, European Society of Medical Oncology has recognized the current and incoming approvals of biosimilars in oncology and issued its own statement that also recognizes the potential for cost savings and the importance of HCP and patient education [3].

The approval of cancer-directed biosimilars such as mAbs is relatively recent and it is too early to assess their impact on the healthcare landscape. Clearly, there is a higher level of concern among clinicians and patients in terms of the utilization of biosimilars and their use in combination therapies as any loss of efficacy or increase in toxicity could have a more direct impact on the patient's disease course and potential curability. It might be anticipated that the uptake in use of these agents will be somewhat slower than that of the supportive care agents or as has been observed in more regulated health systems such as in Europe. Uptake of biosimilars will require time and experience along with continued education efforts providing a full understanding of the rationale for regulatory review and approval and existing favorable experience elsewhere in the world.

As more biosimilars are launched, it would be important to integrate these agents in specific treatment guidelines. There are currently no guidelines on how and when to transition patients from an RP to a biosimilar. It is generally thought that regulatory agency decisions regarding TOE, extrapolation and interchangeability will be accepted by the healthcare community. Establishing registries would provide real-world evidence regarding the routine use of these products.

In conclusion, the availability of biosimilars as a new category of oncologic agents is now a reality. Their adoption in clinical practice will, however, require an increased understanding of what they are, how they are developed, how they are approved and how they can be used in practice. With patent expiration of oncological biologicals estimated to exceed global annual spending of greater than 20 billion USD in the next few years [4], it is thought that biosimilars may eventually gain a significant share of this market. Nevertheless, the impact of biosimilars in the market on drug pricing and overall healthcare costs is not yet clear. Existing experience suggests that it may require more than one competitive biosimilar to begin to drive down drug prices. As more biologics lose patent protection, we can only expect an increase in the availability of such biosimilars and as they become an important part of our treatment armamentarium, education regarding their safe use also becomes important and will be a key factor in assuring safe, cost-effective treatments for our patients. 
Financial \& competing interests disclosure

M Thill is a consultant/advisor for Amgen, AstraZeneca, Celgene, Daiichi Sankyo, Eisai, Genomic Health, Hexal, Lilly, MSD, Myriad, Neodynamics, Novartis, Pfizer, pfm Medical, Roche, RTI Surgical, SurgicEye, Teva; has received speaker honoraria from Amgen, AstraZeneca, Celgene, Eisai, Genomic Health, Hexal, Lilly, Myriad, Neodynamics, Novartis, Pfizer, pfm Medical, Roche, RTI Surgical, SurgicEye, Teva; manuscript support from Amgen, Roche, Celgene; and trial funding from Genomic Health. N Thatcher is a consultant to Amgen, Boehringer Ingelheim, Lilly, Otsuka, Roche and investigator for Amgen. $V$ Hanes is an employee and stockholder of Amgen. GH Lyman has a leadership role at Generex Biotechnology; has received research funding from Amgen (Inst); is a consultant/advisor for G1 Therapeutics, Halozyme Therapeutics, Partners Healthcare, Hexal, Bristol-Myers Squibb, Helsinn Therapeutics, Amgen, Pfizer, Agendia, Genomic Health, Inc. The authors have no other relevant affiliations or financial involvement with any organization or entity with a financial interest in or financial conflict with the subject matter or materials discussed in the manuscript apart from those disclosed.

Writing assistance was utilized in the production of this manuscript.

Open access

This work is licensed under the Attribution-NonCommercial-NoDerivatives 4.0 Unported License. To view a copy of this license, visit http://creativecommons.org/licenses/by-nc-nd/4.0/

\section{Executive summary}

- There is growing awareness of biosimilars as viable treatment options.

- As more biosimilars become available, the need to improve awareness and understanding of these therapeutic alternatives among clinicians and caregivers will continue to increase.

Development \& approval of biosimilars

- Biosimilars are required to undergo rigorous and comprehensive analytical (structural and functional), preclinical and clinical assessment before receiving regulatory approval; regulatory approval is based on the stepwise accumulation and build-up of a totality of evidence, which considers all the available data, including analytical, preclinical, clinical pharmacokinetics/pharmacodynamics and clinical similarity (efficacy, safety and immunogenicity) versus an originator or reference product in a representative indication.

\section{References}

Papers of special note have been highlighted as: $\bullet$ of interest; $\bullet \bullet$ of considerable interest

1. Lyman GH, Balaban E, Diaz M et al. American Society of Clinical Oncology Statement: biosimilars in oncology. J. Clin. Oncol. 36(12), $1260-1265$ (2018).

-. Important statement from the American Society of Clinical Oncology reviewing key concepts in the field of biosimilars and providing clinicians guidance on their use, with specific reference to oncologists.

2. Lyman GH, Zon R, Harvey RD. Rationale, opportunities, and reality of biosimilar medications. N. Engl. J. Med. 379(7), 694-695 (2018).

3. Tabernero J, Vyas M, Giuliani R et al. Biosimilars: a position paper of the European Society for Medical Oncology, with particular reference to oncology prescribers. ESMO Open 1(6), e000142 (2016).

-• Important statement that provides an EU perspective from the European Society of Medical Oncology describing biosimilars, key definitions, responsibilities of prescribers and potential financial impact on healthcare in Europe and globally.

4. IMS Institute for Healthcare Informatics. The global use of medicines: outlook through 2017. (2018). www.statista.com/statistics/280578/global-biologics-spending/

5. The European medicines Agency. Biosimilar medicines. (2017). www.ema.europa.eu/ema/index.jsp?curl = pages/medicines/general/general_content_001832.jsp

6. Uscode.house.gov. 42 US Code $\S 262$ (i)(2) - regulation of biological products. (2018). http://uscode.house.gov/view.xhtml?req = (title:42\%20section:262\%20edition:prelim)

7. US FDA. Guidance for Industry. Biosimilars: questions and answers regarding the implementation of the Biologics Price Competition and Innovation Act of 2009. (2015). www.fda.gov/downloads/drugs/guidances/ucm4446661.pdf

8. Japan Generic Medicines Association. Nov 25, 2010 Interim Translation of Notification ELD, PFSB, MHLW; Yakushokushinsa No0304007. (2009).

9. WHO. Guidelines on evaluation of Similar Biotherapeutic Products (SBPs). (2009). www.who.int/biologicals/areas/biological_therapeutics/BIOTHERAPEUTICS_FOR_WEB_22APRIL2010.pdf 
10. US FDA. Scientific considerations in demonstrating biosimilarity to a reference product (final guidance). www.fda.gov/downloads/Drugs/GuidanceComplianceRegulatoryInformation/Guidances/UCM291128.pdf

- Key regulatory guidance document from the US FDA outlining the requirements and scientific justifications for biosimilar approval.

11. European Medicines Agency. Guideline on similar biological medicinal products containing biotechnology-derived proteins as active substances: quality issues (EMEA/CHMP/BWP/49348/2005) (2016).

www.ema.europa.eu/docs/en_GB/document_library/Scientific_guideline/2009/09/WC500003953.pdf

- Key regulatory guidance document from the EMEA outlining the requirements for producing quality biologicals, including biosimilars.

12. Ministry of Health Labour and Welfare (MHLW). Interim translation. Guidelines for the quality, safety and efficacy assurance of follow-on biologics. No 0304004. MHLW; Tokyo, Japan. (2009) www.pmda.go.jp/files/000153851.pdf

13. Nathan JJ, Ramchandani M, Kaur P. Manufacturing of biologics. In: Biologic and Systemic Agents in Dermatology. Yamauchi P (Ed.). Springer, Cham, Switzerland, 2018.

14. Declerck P, Farouk-Rezk M, Rudd PM. Biosimilarity versus manufacturing change: two distinct concepts. Pharm. Res. 33(2), 261-268 (2016).

15. Yamauchi P, Crowley J, Kaur P, Spelman L, Warren R. Biosimilars: what the dermatologist should know. J. Eur. Acad. Dermatol. Venereol. 32(7), 1066-1074 (2018).

16. Kozlowski S. US FDA perspectives on biosimilar biological products. Presented at: Biotechnology Summit. Rockville, MD, USA, 13 June 2014.

17. Chow SC, Song F, Bai H. Analytical similarity assessment in biosimilar studies. AAPS J. 18(3), 670-677 (2016).

18. Sivendran R, Ramirez J, Ramchandani M, Liu J. Scientific and statistical considerations in evaluating the analytical similarity of ABP 501 to adalimumab. Immunotherapy 10(11), 1011-1021 (2018).

19. Barnes H, Ragnarsson G, Alvan G. Quality and safety considerations for recombinant biological medicines: a regulatory perspective. Int. J. Risk. Saf. Med. 21(1), 13-22 (2009).

20. Kuhlmann M, Covic A. The protein science of biosimilars. Nephrol. Dial. Transplant. 21(Suppl. 5), v4-v8 (2006).

21. Colbert RA, Cronstein BN. Biosimilars: the debate continues. Arthritis Rheum. 63(10), 2848-2850 (2011).

22. European Medicines Agency. Guideline on similar biological medicinal products containing biotechnology-derived proteins as active substance: non-clinical and clinical issues. (2014). www.ema.europa.eu/documents/scientific-guideline/guideline-similar-biological-me dicinal-products-containing-biotechnology-derived-proteins-active_en-0.pdf

23. Abraham I, Sun D, Bagalagel A et al. Biosimilars in 3D: definition, development and differentiation. Bioengineered 4(4), 203-206 (2013).

24. Markus R, Liu J, Ramchandani M, Landa D, Born T, Kaur P. Developing the totality of evidence for biosimilars: regulatory considerations and building confidence for the healthcare community. BioDrugs 31(3), 175-187 (2017).

-. Comprehensive review of the scientifically robust and step-wise approach to developing and manufacturing biosimilars, the concept of totality of evidence to support regulatory approval and the practical challenges in implementing it and consistently producing quality biosimilars.

25. Declerck PJ. Biosimilar monoclonal antibodies: a science-based regulatory challenge. Exp. Opin. Biol. Ther. 13(2), $153-156$ (2013).

26. Vu T, Claret FX. Trastuzumab: updated mechanisms of action and resistance in breast cancer. Front. Oncol. 2(62), (2012).

27. Spector N, Blackwell K. Understanding the mechanisms behind trastuzumab therapy for human epidermal growth factor receptor 2-positive breast cancer. J. Clin. Oncol. 27(34), 5838-5847 (2009).

28. Baselga J, Albanell J, Molina MA, Arribas J. Mechanism of action of trastuzumab and scientific update. Semin. Oncol. 28(5 Suppl. 16), 4-11 (2001).

29. Weiner GJ. Rituximab: mechanism of action. Semin. Hematol. 47(2), 115-123 (2010).

30. European Medicines Agency. Guideline on similar biological medicinal products containing biotechnology-derived proteins as active substances: nonclinical and clinical issues (EMEA/CHMP/BMWP/42832/2005). (2013). www.ema.europa.eu/docs/en_GB/document_library/Scientific_guideline/2009/09/WC500003920.pdf

31. US FDA. Guidance for industry: clinical pharmacology data to support demonstration of a biosimilar to a reference product, 2016. www.fda.gov/downloads/Drugs/GuidanceComplianceRegulatoryInformation/Guidances/UCM397017.pdf

32. International Council for Harmonisation of Technical Requirements for Pharmaceuticals for Human Use (ICH). Harmonised Tripartite Guideline: choice of control group and related issues in clinical trials E10. (2000). www.ich.org/fileadmin/Public_Web_Site/ICH_Products/Guidelines/Efficacy/E10/Step4/E10_Guideline.pdf

33. International Council for Harmonisation of Technical Requirements for Pharmaceuticals for Human Use (ICH). Harmonised Tripartite Guideline: statistical principles for clinical trials E9. (1997). www.ich.org/fileadmin/Public_Web_Site/ICH_Products/Guidelines/Efficacy/E9/Step4/E9_Guideline.pdf 
34. Cortes J, Curigliano G, Dieras V. Expert perspectives on biosimilar monoclonal antibodies in breast cancer. Breast Cancer Res. Treat. 144(2), 233-239 (2014).

35. Thill M. New frontiers in oncology: biosimilar monoclonal antibodies for the treatment of breast cancer. Exp. Rev. Anticancer Ther. 15(3), 331-338 (2015).

- Review of monoclonal antibody biosimilars in oncology, with specific reference to trastuzumab and its use in breast cancer.

36. Cortazar P, Geyer CE Jr. Pathological complete response in neoadjuvant treatment of breast cancer. Ann. Surg. Oncol. 22(5), 1441-1446 (2015).

37. Jackisch C, Scappaticci FA, Heinzmann D et al. Neoadjuvant breast cancer treatment as a sensitive setting for trastuzumab biosimilar development and extrapolation. Future Oncol. 11(1), 61-71 (2015).

- A literature review that discusses the best approach to designing clinical trials that can document clinical similarity (including efficacy and immunogenicity) between a potential biosimilar and its reference product and highlights the neoadjuvant breast cancer setting as being a sensitive setting in this regard.

38. von Minckwitz G, Colleoni M, Kolberg HC et al. Efficacy and safety of ABP 980 compared with reference trastuzumab in women with HER2-positive early breast cancer (LILAC study): a randomised, double-blind, Phase III trial. Lancet Oncol. 19(7), 987-998 (2018).

- A Phase III study in the sensitive neoadjuvant setting, with a first-time use of central pathology review to minimize interpathologist variability in clinical trials that also included an investigation of the potential outcomes of switching between a reference product and its biosimilar in the adjuvant phase.

39. Radstake TR, Svenson M, Eijsbouts AM et al. Formation of antibodies against infliximab and adalimumab strongly correlates with functional drug levels and clinical responses in rheumatoid arthritis. Ann. Rheum. Dis. 68(11), 1739-1745 (2009).

40. Moxness M, Tatarewicz S, Weeraratne $\mathrm{D}$ et al. Immunogenicity testing by electrochemiluminescent detection for antibodies directed against therapeutic human monoclonal antibodies. Clin. Chem. 51(10), 1983-1985 (2005).

41. Kaur P, Chow V, Zhang N, Moxness M, Kaliyaperumal A, Markus R. A randomised, single-blind, single-dose, three-arm, parallel-group study in healthy subjects to demonstrate pharmacokinetic equivalence of ABP 501 and adalimumab. Ann. Rheum. Dis. 76(3), 526-533 (2017).

42. O'Shaughnessy J, Blackwell KL, Burstein $\mathrm{H}$ et al. A randomized study of lapatinib alone or in combination with trastuzumab in heavily pretreated HER2+ metastatic breast cancer progressing on trastuzumab therapy. J. Clin. Oncol. 26, 1015 (2008).

43. Portera CC, Swain SM. The heart of the matter. J. Clin. Oncol. 25(25), 3794-3796 (2007).

44. Baselga J, Tabernero J. Combined antiangiogenesis and antiepidermal growth factor receptor targeting in the treatment of cancer: hold back, we are not there yet. J. Clin. Oncol. 25(29), 4516-4518 (2007).

45. Kummel S, Wimberger P, Von Minckwitz G, Nekljudova V, Denkert C, Just M. Investigating denosumab as an add-on neoadjuvant treatment for RANK/L-positive or RANK/L-negative primary breast cancer and two different nab-paclitaxel schedules: $2 \times 2$ factorial design (GeparX) - an interim safety analysis. J. Clin. Oncol. 36, Abstract 569 (2018).

46. Cohen H, Beydoun D, Chien D et al. Awareness, knowledge, and perceptions of biosimilars among specialty physicians. Adv Ther. 33(12), 2160-2172 (2017).

47. Weise M, Kurki P, Wolff-Holz E, Bielsky MC, Schneider CK. Biosimilars: the science of extrapolation. Blood 124(22), 3191-3196 (2014).

48. Smith MR. Rituximab (monoclonal anti-CD20 antibody): mechanisms of action and resistance. Oncogene 22(47), 7359-7368 (2003).

49. Government Publishing Office [US]. Patient Protection and Affordable Care Act. (2010). www.gpo.gov/fdsys/pkg/PLAW-111publ148/html/PLAW-111publ148.htm

50. US FDA. Guidance for Industry. Considerations in demonstrating interchangeability with a reference product. (2017). www.fda.gov/downloads/Drugs/GuidanceComplianceRegulatoryInformation/Guidances/UCM537135.pdf

51. Jorgensen KK, Olsen IC, Goll GL et al. Switching from originator infliximab to biosimilar CT-P13 compared with maintained treatment with originator infliximab (NOR-SWITCH): a 52-week, randomised, double-blind, non-inferiority trial. Lancet 389(10086), 2304-2316 (2017).

52. Cohen HP, Blauvelt A, Rifkin RM, Danese S, Gokhale SB, Woollett G. Switching reference medicines to biosimilars: a systematic literature review of clinical outcomes. Drugs 78(4), 463-478 (2018).

53. Gerdes S, Thaci D, Griffiths CEM et al. Multiple switches between GP2015, an etanercept biosimilar, with originator product do not impact efficacy, safety and immunogenicity in patients with chronic plaque-type psoriasis: 30-week results from the Phase III, confirmatory EGALITY study. J. Eur. Acad. Dermatol. Venereol. 32(3), 420-427 (2018).

54. Blackwell K, Gascon P, Krendyukov A et al. Safety and efficacy of alternating treatment with EP2006, a filgrastim biosimilar, and reference filgrastim: a Phase III, randomised, double-blind clinical study in the prevention of severe neutropenia in patients with breast cancer receiving myelosuppressive chemotherapy. Am. Oncol. 29(1), 244-249 (2018).

55. GaBI Online. Legislations on biosimilar interchangeability in the US and EU - developments far from visibility. (2015). www.gabionli ne.net/Sponsored-Articles/Legislations-on-biosimilar-interchangeability-in-the-US-and-EU-developments-far-from-visibility 
56. US FDA. Guidance for industry. Nonproprietary naming of biological products. (2017). www.fda.gov/downloads/drugs/guidances/ucm459987.pdf

57. Europa BioGuide on Biosimilars - EuropaBio. Guide to biological medicines. (2011). www.europabio.org/guide-biological-medicines-focus-biosimilar-medicines

58. Moorkens E, Jonker-Exler C, Huys I, Declerck P, Simoens S, Vulto AG. Overcoming barriers to the market access of biosimilars in the European Union: the case of biosimilar monoclonal antibodies. Front. Pharmacol. 7, 193 (2016).

59. Monk BJ, Lammers PE, Cartwright T, Jacobs I. Barriers to the access of bevacizumab in patients with solid tumors and the potential impact of biosimilars: a physician survey. Pharmaceuticals 10(1), pii E19 (2017). 
